\title{
Estratégias pedagógicas para o desenvolvimento da competência ético-política na formação inicial em Enfermagem
}

\author{
Pedagogical strategies for developing ethical and political competence in nursing education \\ Estrategias pedagógicas para el desarrollo de la competencia ética y política en la \\ formación inicial en Enfermería
}

\section{Juliane Cristina Burgatti', Valéria Marli Leonello', Luzmarina Aparecida Doretto Bracialli", Maria Amélia de Campos Oliveira"' \\ ' Universidade de São Paulo, Escola de Enfermagem, Programa de Pós-Graduação em Enfermagem (Doutoranda). São Paulo-SP, Brasil. \\ "Faculdade de Medicina de Marília, Curso de Enfermagem. Marília-SP, Brasil. \\ "' Universidade de São Paulo, Escola de Enfermagem, Departamento de Enfermagem em Saúde Coletiva, Programa de Pós-Graduação em Enfermagem. São Paulo-SP, Brasil.}

\author{
Submissão: 04-07-2011 Aprovação: 29-03-2013
}

\section{RESUMO}

Este estudo apresenta uma reflexão teórica que objetiva evidenciar estratégias pedagógicas para o desenvolvimento da dimensão ético-política da competência profissional sob a perspectiva da reflexão crítica. A competência profissional possui dupla dimensão - técnica e política, mediada pela ética. A reflexão crítica busca renovar formas de pensar e fazer em saúde, tendo como finalidade última a intervenção na realidade social, para aprimorar as condições de vida e saúde das coletividades. Destacam-se alguns instrumentos educacionais como o portfólio, o diário de campo e as narrativas escritas, que permitem produzir um relato claro e objetivo da experiência e atribuir sentido e significado ao que foi realizado. Calcados na reflexão crítica, tais instrumentos favorecem o desenvolvimento dimensão ético-política da competência profissional.

Descritores: Competência Profissional; Ética; Educação em Enfermagem.

\begin{abstract}
This study presents a theoretical reflection that aims at identifying teaching strategies for the development of ethical-political dimension of professional competence from the perspective of critical reflection. Professional competence has two dimensions - technical and political, mediated by ethics. Critical reflection renew search ways of thinking and doing in health, with the ultimate goal of intervention in social reality, to improve the living conditions and health of communities. Highlights some educational tools such as portfolio, the field journal and written narratives, which allow producing a clear and objective account of the experience and assigning meaning and significance of what was accomplished. Based on a critical reflection, such instruments helped develop ethical-political dimension of professional competence.
\end{abstract}

Key words: Professional Competence; Ethics; Nursing Education.

\section{RESUMEN}

Este estudio presenta una reflexión teórica que tiene como objetivo identificar las estrategias de enseñanza para el desarrollo de la dimensión ético-política de la competencia profesional desde la perspectiva de la reflexión crítica. La competencia profesional tiene dos dimensiones - técnicos y políticos, mediadas por la ética. La reflexión crítica renovar formas de búsqueda de pensar y hacer en la salud, con el objetivo final de la intervención en la realidad social, para mejorar las condiciones de vida y de salud de las comunidades. Destaca algunas herramientas educativas como de cartera, el diario de campo y narrativas escritas, que permiten producir una descripción clara y objetiva de la experiencia y asignar significado y la importancia de lo que se logró. Basado en la reflexión crítica, estos instrumentos ayudaron a desarrollar la dimensión ético-política de la competencia profesional

Palabras clave: Competencia Profesional; Ética; Educación Enfermería.

\section{AUTOR CORRESPONDENTE Juliane Cristina Burgatti E-mail: juliburgatti@uol.com.br}




\section{INTRODUÇÃO}

A formação inicial em Enfermagem vem sendo instada a responder ao desafio de formar profissionais competentes para o trabalho em saúde. A Resolução do Conselho Nacional de Educação (CNE) / Câmara de Educação Superior (CES) $n^{\circ}$ 03, de 07 de novembro de 2001, que instituiu as Diretrizes Curriculares Nacionais do Curso de Graduação de Enfermagem, definiu o perfil profissional a ser formado: enfermeiros generalistas, humanistas, críticos e reflexivos, o que leva a questionar quais os significados atribuídos à crítica e à reflexão, para além do senso comum ${ }^{(1)}$.

Para o desenvolvimento do perfil profissional almejado, é preciso aprofundar as questões referentes ao processo ensino e aprendizagem. Se há necessidade de formar enfermeiros competentes nas dimensões técnica, científica, ética e política, sujeitos sociais com capacidade de atuar em contextos de incertezas e complexidade, pergunta-se: que estratégias pedagógicas podem ser utilizadas para esse fim?

Esta reflexão teórica objetiva evidenciar estratégias pedagógicas para o desenvolvimento da dimensão ético-política da competência profissional. Para discutir essas estratégias será abordada a competência profissional, em especial sua dimensão ética e política, e será destacada a teoria da reflexão crítica na ação e sobre a ação, proposta pelo educador urbano norte-americano Donald Schön.

Sua importância reside em problematizar a dimensão ética e política da competência profissional e propor caminhos pedagógicos para favorecer seu desenvolvimento na formação inicial em Enfermagem, a fim de romper um círculo vicioso de justificativas para a ausência de postura crítica e reflexiva por parte dos profissionais.

\section{A NOÇÃO DE COMPETÊNCIA PROFISSIONAL}

Competência é um vocábulo de origem latina, que tem dois sentidos: pode ser compreendida como a faculdade atribuída a alguém para apreciar e julgar um pedido ou questão como, por exemplo, "o juiz é competente para julgar esta causa", ou ainda como "conhecimento, capacidade ou habilidade da pessoa em resolver problemas, realizar uma atividade"(2).

Competência é sinônimo de "saber fazer bem feito" e possui dupla dimensão: técnica e política. A primeira refere-se ao domínio de conteúdos, técnicas e estratégias. A segunda diz respeito ao aspecto valorativo da atuação, o posicionamento profissional. E a mediação entre essas duas dimensões é realizada pela ética ${ }^{(3)}$.

Além de conhecimentos teóricos e práticos, o exercício profissional requer qualidades, capacidades, habilidades e atitudes relacionadas a esses conhecimentos, que conformam a competência(2).

O relatório da Conferência Internacional sobre Educação para o século XXI, coordenado por Jacques Delors, menciona que o que torna um profissional competente é articulação dos quatro pilares da educação: saber-conhecer, saber-fazer, saber-ser e saber-conviver ${ }^{(4)}$.

A formação baseada na competência compreende a articulação desses pilares: aprender a conhecer e aprender a fazer, para poder agir sobre o contexto em que se vive; aprender a viver em coletividade, a fim de participar da vida em sociedade e colaborar com todos os seres humanos, e aprender a ser, que engloba os três saberes anteriores ${ }^{(4)}$. As dimensões ética e política da competência profissional integram elementos do aprender a ser e a conviver, expressos nas atitudes e valores, no modo de lidar e resolver as diversas situações complexas encontradas no mundo do trabalho.

Na formação em Enfermagem, o aprender a fazer é bastante destacado. Contudo, para ser competente, não basta ao profissional ter conhecimentos e habilidades para fazer seu ofício. É preciso saber fazê-lo bem, o que implica querer fazer e poder fazê-lo, em face de limites e possibilidades do contexto em que realiza a ação profissional ${ }^{(3)}$.

A intencionalidade é um componente essencial na ação ético-política. Para que uma ação seja qualificada como competente é de suma importância a decisão do que fazer com o saber, para que o saber e o saber-fazer não tenham sentidos isolados. A intencionalidade presente no saber-fazer distancia a educação de uma suposta neutralidade $\mathrm{e}^{(3)}$. O posicionamento ético-político do profissional, aliado ao comprometimento social, é uma atitude fundamental para o desenvolvimento da competência profissional nos diferentes contextos do trabalho em saúde.

\section{A AÇÃO EDUCATIVA NO PROCESSO DE DESENVOLVI- MENTO DA DIMENSÃO ÉTICO-POLÍTICA DA COMPE- TÊNCIA PROFISSIONAL}

Para favorecer o desenvolvimento da dimensão ético-política da competência profissional, com a finalidade de intervenção na realidade social, a educação precisa ser propulsora do desenvolvimento humano, constituída por um processo contínuo, amplo e profundo de preparação dos indivíduos ao longo da vida.

No processo de ensino e aprendizagem, a comunicação precisa ser considerada em seu sentido verdadeiro para sustentar e desenvolver a relação entre estudantes e docentes, implicando, por parte do professor, atitudes em que a sensibilidade e a emoção são instrumentos para ampliar as formas de pensar, investigar e cuidar, estimulando o potencial criativo dos educandos e sua auto-governabilidade, a manifestação de suas opiniões, fortalecendo o desenvolvimento da autonomia, da solidariedade e do respeito mútuo ${ }^{(5)}$.

No processo de desenvolvimento da dimensão ético-política da competência profissional, educador e educando ocupam papel importante no cenário da instituição de ensino. $\mathrm{O}$ professor é um co-gestor do processo de ensino e aprendizagem dos estudantes e atua como mediador entre o conhecimento disponível e as exigências da prática profissional, além de ser uma referência ética e política para os estudantes. Estes, por sua vez, são protagonistas do seu processo de formação e observam os exemplos dos profissionais que atuam nas instituições de ensino e nos campos de estágios.

Toda prática educativa requer a existência de sujeitos que, ensinando, aprendem e que, aprendendo, ensinam. Disso decorre o cunho gnosiológico da educação, uma vez que a finalidade última dos processos educativos é o conhecimento, 
no sentido formativo e informativo. Nossas concepções estão estreitamente ligadas à Teoria do Conhecimento ou Gnosiologia (do grego gnôsis, conhecimento) e fazem parte do que anteriormente se denominava Filosofia da Ciência e, mais contemporaneamente, de uma área multidisciplinar chamada Epistemologia (do grego epistéme, ciência) ${ }^{(6)}$.

A prática educativa também é diretiva e política, dado que a atividade do professor não é neutra e tampouco circunscrita à transmissão dos conteúdos. Os educadores apresentam uma autonomia relativa na interação entre escola e sociedade ${ }^{(6)}$. Essa relação propõe uma unidade dialética, um ensino em que o papel de condutor do professor e a atividade do estudante acontecem em uma via de mão dupla ${ }^{(7)}$.

A prática docente crítica envolve um movimento dinâmico e dialético entre o fazer e o pensar sobre o fazer. Uma prática docente baseada em um saber espontâneo resulta em saber empírico, fruto da experiência, mas sem rigorosidade metodo$\operatorname{lógica}^{(7)}$. A consciência da dimensão ética e política da ação docente na prática educativa pode auxiliar no processo de ensino e aprendizagem.

É necessário possibilitar que a curiosidade ingênua do estudante transforme-se em crítica, em curiosidade epistemológica $^{(8)}$, por meio da reflexão sobre a prática, pois é pensando criticamente a prática de hoje ou de ontem que é possível aperfeiçoá-la para o futuro.

O processo de ensinar para a mudança envolve esforços e atitudes tanto dos educadores quanto dos educandos. É um processo que depende do professor sustentar seus conteúdos com elementos históricos, nexos internos, pesquisas científicas e relacioná-los com os contextos onde tais conteúdos apresentam-se. E depende da atitude ativa do estudante atribuir sentido e significado ao que aprende a fazer, interrogando-se continuamente sobre o porquê de determinada ação.

O processo de ensinar e aprender restrito ao universo técnico não é suficiente para superar, no sentido dialético do termo, os padrões estabelecidos e as formas consagradas de pensar e fazer. Somente a reflexão crítica, aliada ao compromisso genuíno com a sociedade, pode ser agente de mudanças socioculturais. "Transformar a experiência educativa em puro treinamento técnico é amesquinhar o que há de fundamentalmente humano no exercício educativo: o seu caráter formador"(8).

\section{A NOÇÃO DE REFLEXÃO CRÍTICA}

Na ação profissional, como no aprendizado, a experiência geralmente é visualizada, compreendida e descrita em termos basicamente cognitivos. Isto ocorre especialmente no contexto do aprendizado, em que a ação segue modelos técnico-racionais de entendimento. No aprendizado reflexivo, as respostas cognitivas são importantes, porém os pensamentos e os sentimentos também devem ser considerados, pois estão interconectados às ações, por meio de caminhos altamente complexos ${ }^{(9)}$.

A reflexão crítica envolve a exploração dos sentimentos, que constituem uma parte importante das experiências vividas e, assim como os pensamentos e as ações, auxiliam formar a experiência particular. Os sentimentos influenciam a motivação para agir e, consequentemente, o processo cognitivo ${ }^{(9)}$.
A reflexão sobre os pensamentos e as experiências oferece a oportunidade de mudar o que pensamos e fazemos. Situações passadas podem ajudar a solucionar desafios futuros. Para isso, é preciso passar pela experiência, registrá-la e retornar a ela, de modo a compreender mais profundamente os eventos ocorridos e ser capaz de utilizar entendimentos anteriores para maneiras novas e mais efetivas de agir para o futuro $^{(9)}$. Para que o processo reflexivo sobre a ação ocorra, é necessário reconhecer crenças, atitudes e valores e conectá-los à experiência. Para isso, é preciso considerar os espaços mental, emocional e físico no qual a complexidade de pensamentos, sentimentos e ações adquire sentido.

O processo da aprendizagem reflexiva é denominado por Schön de "reflexão na ação". Segundo Schön, professor norte-americano de estudos urbanos e educação, há um conhecimento tácito nas ações que é demonstrado espontaneamente, como, por exemplo, ao andar de bicicleta. Ao descrever o conhecimento tácito que é subjacente à ação, ocorre um processo de reflexão ${ }^{(10)}$.

A reflexão na ação é significativa para o evento porque ocorre no momento em que o indivíduo está realizando a ação e ainda há a oportunidade de fazer a diferença no local e no momento, pois ocorre ao mesmo tempo em que a ação está em execução, sem interrompê-la, porém com breves instantes de distanciamento ${ }^{(10)}$.

Difere da reflexão sobre a ação, que ocorre após a ação ter ocorrido e permite mudar apenas as ações futuras. A distância do evento passado permite examiná-lo como um observador da própria experiência, o que favorece a construção da competência, particularmente a dimensão ético-política Em situações não familiares ou incertas, a reflexão na e sobre a ação é importante para fazer alterações e mudanças nas ações presentes e futuras ${ }^{(10)}$.

\section{ESTRATÉGIAS PARA O DESENVOLVIMENTO DA REFLEXÃO CRÍTICA NA FORMAÇÃO INICIAL EM ENFERMAGEM}

Na saúde, o desenvolvimento do processo de análise e reflexão deveria permitir aumentar o entendimento sobre relatos empíricos e teóricos complexos, de modo a responder aos problemas de saúde não somente em termos técnicos, mas também em termos de crenças e valores próprios do campo profissional ${ }^{(9)}$.

Para o engajamento na reflexão, dois requisitos cruciais são identificados: primeiro, é necessário um relato claro e objetivo da experiência que está em reflexão e, segundo, é preciso atribuir sentido e significado ao que foi realizado. A escrita reflexiva faz uso destes tipos de questões para estimular pensamentos e reações.

Durante a formação, os estudantes podem produzir relatos por escrito das experiências vividas, compondo um diário de campo ou um portfólio reflexivo. Um diário escrito envolve elementos de reflexão e registra as experiências significativas tão logo quanto possível. Também pode ser útil incluir, além da descrição da ação, questões como: como você se sentiu com a experiência? Foi boa ou ruim? O que você aprendeu com ela? Você poderia ter feito de outra maneira? ${ }^{(9)}$

A distinção entre o diário de campo e o portfólio reflexivo é 
que este último é uma atividade realizada com menos imediatismo, que propicia ao estudante a oportunidade para construir uma resposta à experiência e analisá-la, além de dar a estudantes e professores a oportunidade de realizar uma avaliação mais sistemática, envolvendo a integração entre teoria e literatura para o entendimento do quê e por quê aconteceu ${ }^{(9)}$.

A narrativa escrita é uma alternativa utilizada para promover a reflexão e o aumento da autoconsciência. Uma pesquisa qualitativa envolvendo trinta e dois estagiários de nove programas de residência médica, acompanhados ao longo de um ano, foi realizada para determinar o impacto da narrativa escrita sobre a reflexão. A cada oito semanas, os estagiários registraram por escrito suas experiências. A narrativa revelou-se estratégia útil, que pode ser incorporada pelos educadores na residência, uma vez que permite a reflexão. Nesse estudo em particular, em que estagiários foram incentivados a repensar seus valores essenciais e prioridades, alguns demonstraram que o exercício de escrever sobre experiências difíceis promove maior autoconsciência e induz à reflexão(11).

Em um levantamento bibliográfico realizado na Biblioteca Virtual em Saúde (BIREME) usando os descritores portfólio reflexivo (PR) foram identificados doze artigos (um em duplicidade), dentre o período de 2008 a 2012, sendo que cinco estudos que tiveram como participantes estudantes de Enfermagem apontaram o PR como um instrumento de autorreflexão da aprendizagem ${ }^{(12-16)}$.

Em um estudo brasileiro realizado sobre o uso do portfólio reflexivo na ótica de docentes de Medicina e Enfermagem de uma instituição de ensino superior que utiliza metodologias ativas de aprendizagem, este foi visto como um instrumento inovador, que requer dedicação dos docentes, estimula a reflexão dos estudantes e permite seu acompanhamento pessoal e profissional $^{(14)}$.

Dois estudos sobre a percepção do uso do portfólio reflexivo por estudantes de medicina revelaram que, embora seja um instrumento de aprendizagem ativa, os estudantes têm dificuldades para identificar sua contribuição para o desenvolvimento da capacidade reflexiva ${ }^{(17-18)}$.

Outra investigação realizada com graduandos de Enfermagem considerou o portfolio um instrumento de reflexão que exige tempo e habilidades de escrita ${ }^{(16)}$. Sua utilização por estudantes não habituados pode causar impactos negativos inicialmente $^{(14)}$. Daí a necessidade da mediação realizada pelo docente no intuito de fornecer feedbacks, enriquecer a narrativa com novas perspectivas, salientar lacunas, apresentar alternativas. Somente nessa condição o portfólio tem finalidade de reflexão ou de avaliação formativa.
Se bem utilizado, o portfólio é uma estratégia relevante para a formação reflexiva, possibilitando ao estudante conhecer seu processo de aprendizagem e praticar a reflexão-ação-reflexão. É um valioso instrumento de mão dupla porque permite ao docente verificar o desenvolvimento do estudante em todos os aspectos da competência profissional - técnica, ética e política, e possibilita ao estudante um processo de progressão, construção e reconstrução das várias dimensões de sua competência profissional.

O importante é que os estudantes lidem com suas experiências formativas de forma ampla e profunda, tendo a oportunidade de discutir com seus professores e também com os profissionais dos serviços de saúde as diferentes formas de encaminhamento de um problema ou questão.

\section{CONSIDERAÇÕES FINAIS}

O processo reflexivo é cada vez mais valorizado na prática educativa. Sua finalidade é formar profissionais criativos, curiosos epistemologicamente e capazes de transformar a realidade. Entretanto, poucos são os textos que fazem referência a como favorecer o desenvolvimento da dimensão ético-política da competência na formação em saúde.

A articulação do referencial teórico de competência que se desenvolve na ação com a vertente teórica da reflexão na ação e sobre ação permite aproximações para a construção de posturas e atitudes comprometidas socialmente.

Partindo das noções de competência e sua dimensão ético-política, a presente reflexão teórica destacou estratégias pedagógicas como possibilidades para o desenvolvimento da competência ético-política na formação inicial em Enfermagem. Fundamentadas na teoria da reflexão na e sobre a ação, estratégias tais como o portfólio, o diário de campo e as narrativas escritas permitem produzir um relato claro e objetivo da experiência e atribuir-lhe sentido e significado.

Para desenvolver atitudes ético-políticas, o registro por escrito de experiências vivenciadas pelos estudantes no ensino prático em campo e o acompanhamento desses registros por parte dos professores podem se revelar um círculo virtuoso entre o pensamento crítico e reflexivo e ação ético-política de futuros profissionais de saúde.

Muitas vezes, o ensino prático em campo é visto como mera aplicação de um saber disciplinar. Contudo, a prática em saúde é sempre interdisciplinar, o que lhe confere uma característica integradora de conhecimentos e habilidades de distintas áreas disciplinares, aliada a atitudes ético-políticas tão necessárias à competência profissional em Enfermagem.

\section{REFERÊNCIAS}

1. Ministério da Educação (Brasil). Resolução $n^{\circ} \cdot 3$, de 07 de novembro de 2001. Institui diretrizes curriculares nacionais do curso de graduação em enfermagem. Diário Oficial da União 9 nov 2001;seção 1.

2. Libâneo JC. Organização e gestão da escola: teoria e prática. 5. ed. São Paulo: Alternativa; 2004.
3. Rios TA. Ética e competência. 18. ed. São Paulo: Cortez; 2008.

4. Delors J. Educação: um tesouro a descobrir: Relatório para a UNESCO da Comissão Internacional sobre Educação para o Século XXI. 8. ed. São Paulo: Cortez; 2003. 
5. Reibnitz KS, Prado ML. Profissional crítico-criativa em enfermagem: a construção do espaço interseçor na relação pedagógica. Rev Bras Enferm 2004;57(6):439-42.

6. Cortella MS. A escola e o conhecimento: fundamentos epistemológicos e políticos. 3. ed. São Paulo: Cortez: Instituto Paulo Freire; 2000.

7. Anastasiou LGC. Processos de ensinagem na universidade: pressupostos para estratégias de trabalho em sala de aula. 6. ed. Joinville: Univille; 2006.

8. Freire P. Pedagogia da autonomia: saberes necessários à prática educativa. 37. ed. São Paulo: Paz e Terra S/A; 2008.

9. Duncan P. Critical perspectives on health. Oxford: Palgrave macmillan; 2007.

10. Schön D. Educando o profissional reflexivo: um novo design para o ensino e a aprendizagem. Porto Alegre: Artes Médicas; 2000.

11. Levine RB, Kern DE, Wright SM. The impact of prompted narrative writing during internship on reflective practice: a qualitative study. Adv Health Sci Educ Theory Pract 2008;13:723-733.

12. Guillaumet Olives M. La carpeta de aprendizaje. Innovación docente en relación de ayuda . Rev Enferm
2011;34(7):506-511.

13. Prearo AY, Monti FMF, Barragan E. É possível desenvolver a autorreflexão no estudante de primeiro ano que atua na comunidade? um estudo preliminar. Rev Bras Educ Méd 2012;36(1): 24-31.

14. Silva RF, Sá-Chaves I. Formação reflexiva: representações dos professores acerca do uso de portfólio reflexivo na formação de médicos e enfermeiros. Interface Comun Saúde Educ 2008; 12(27):721-734.

15. Serrano-Gallardo P, Martínez-Marcos M, Arroyo-Gordo MP, Lanza-Escobedo D. Análisis del portafolio como herramienta evaluativa de las prácticas clínicas de enfermería comunitaria en estudiantes de pregrado. Educ Med 2010;13(3):177-185.

16. Tanji S, Silva CM, Dantas SLM. As potencialidades e fragilidades do portfólio reflexivo na visão dos estudantes de enfermagem. Rev Enferm UERJ 2008;16(3):392-398.

17. Silva RF, Francisco M. A. Portfólio reflexivo: uma estratégia para a formação em medicina. Rev Bras Educ Méd 2009;33(4):562-570.

18. Marin MJS, Moreno TB, Moravcik MY, Higa EFR, Druzian $\mathrm{S}$, Francischetti I, et al. O uso do portfólio reflexivo no curso de medicina: percepção dos estudantes. Rev Bras Educ Méd 2010;34(2):191-198. 